\title{
THE ROLE OF COUNTERPART FUNDS IN ECONOMIC DEVELOPMENT
}

\section{Henry J. Bruton and Catharine B. Hill}

\section{INTRODUCTION}

The purpose of this article is to establish the principal theoretical and conceptual aspects of counterpart funds. We begin with definitions and distinctions, and then examine the rationale of the creation and use of such funds. In the last section we elaborate on what we think to be the basic argument justifying their use, and provide a few examples of this use.

a Definitions. Counterpart funds refer to the local currency of a country that has been accumulated by the sale of commodities or foreign exchange received as aid (or soft loans), and over whose use the donor has some control. The key considerations that distinguish counterpart funds from other domestic currencies are that they are created by the sale of aid-provided commodities or foreign exchange and that the aid donor has some control over their use. Also of importance is the fact that counterpart funds are not generated by any productive process, a fact that has consequences for possible inflationary and deflationary effects of the creation and use of these funds.

b The Basic Question. There are a variety of specific technical issues associated with counterpart funds on which there is general agreement, along with some considerable confusion. These were reviewed in an earlier article in this Bulletin. Here we consider whether or not the whole process, the whole idea, of generating and programming counterpart funds is useful.

There are two main roles that counterpart funds perform. They are a way of getting local currency into the hands of the aid receiving government, and they may provide the donor with some continuing influence over the way some domestic resources in the recipient country are used. The basic question then becomes: Does the counterpart fund arrangement add significantly to the effectiveness of the aid effort and, more specifically, to the development effort of the aid receiving country? The answer (surprise ! surprise !) is that it all depends. We consider on what it depends in the following section.

c Administrative Questions. There are numerous questions that have emerged in the managing and monitoring of counterpart funds. Such questions have to do with the pricing of aid commodities in the recipient's markets, the appropriate exchange rate to use when converting cash foreign aid to the currency of the recipient, the ownership of the funds, and numerous other similar matters. Though these questions are essentially administrative and management issues, their resolution has often affected the way the funds were in fact used. They are discussed more fully in another article in this Bulletin.

\section{HOW COUNTERPART FUNDS WORK}

The exact way that counterpart funds affect the aid effort depends on a number of considerations, in particular on the state of the economy of the aid receiving country. It is helpful to consider a number of idealized cases.

\subsection{An Economy in Equilibrium}

It is useful to begin with an extreme case in which it can easily be seen that counterpart funds are nothing but a nuisance. Imagine an economy in which all markets clear at full employment of labour and full utilization of capital and there is no inflation. There is a sustainable equilibrium in the balance of payments, maintained by exchange rate policy and long run aid and capital inflows. There are no exchange controls or tariffs. There are no institutional or legal barriers that create artificial impediments to the effective use of conventional policy tools. Finally, and of great importance, there is agreement between donor and recipient on what development is and how it can be accomplished. This well-managed economy is, however, extremely poor, hence the foreign aid. We assume that the aid is additional, that is it adds to the amount of resources already available in the country.

The donor plays two roles. It has a key role in determining what commodities are included in the aid package, and, given the existence of the counterpart fund process, it has a say in the use of the funds generated by the sale of aid commodities by the recipient. Under present assumptions, what is the value of this latter role? The answer appears to be that the value is essentially nil. If the recipient can do all that is necessary to use the aid effectively, then the 'seat at the policy table' provided by the counterpart funds is not relevant, and is certainly not worth the cost and friction produced by the administrative costs associated with the process. More generally, we can say that there is no role for counterpart funds simply because the government can do whatever is appropriate (in the 
opinion of both the donor and the recipient) without going through the counterpart fund routine.

These assumptions are helpful in tracing out the effects of aid and counterpart funds on the demands for policy.

There are two immediate consequences of commodity aid. The first is that there are more goods and services available without increased production, i.e. without income being generated in their production. Obviously this has a deflationary impact. The government now has more local currency than it did before the aid, the availability of goods and services has increased by the amount of aid, and the private sector has less purchasing power. This last result also will be deflationary. It is evident that the availability of goods and services has increased by the amount of aid, not by the amount of the aid plus the counterpart funds. The deflationary impact is however greater, and exceeds the amount of counterpart funds generated. This, of course, follows from the fact that aid commodities are supplied in addition to the existing supply of goods and services at the same time that money is withdrawn from the income stream by the sale of the aid commodities in the private sector.

What should the government do? It may in fact do nothing, not increase its spending at all. In an economy in which all markets clear quickly and painlessly, this would mean that wage rates and prices would fall quickly without resulting in any unemployment or underutilization. With an unchanged exchange rate, this would constitute a strong export promotion policy. This might be a useful policy change, but one would have to look at other aspects of the economy to be sure.

Even if a government believed that the above listed assumptions were in fact applicable, it would be a bold government that would choose not to increase its spending in order to achieve such an export promotion policy. The counterpart fund mechanism is designed to put additional spending power into the country and, particularly, into the hands of the government. In as smooth a working economy and economic policy making environment as is presently assumed, the government could accomplish this without counterpart funds. A government can always increase the availability of domestic funds to itself. This is the point that numerous observers have made. (See Lewis 1962; Little and Clifford 1965; Mason 1960; Singer 1964.)

The question, 'what should the government do?' in the context of the present assumptions is fundamental, because it directs attention specifically to how development takes place or could take place in the specific country. The question is brought to the fore by present assumptions because there are no other problems - inflation, price distortions, balance of payments crisis, etc. - that seem urgent: the real question is laid bare before donor and recipient alike. We return to this question in the final section of this article. The present context brings out the importance of the assumption that donor and recipient agree on development policy. Before doing that we want to examine the role of counterpart funds under assumptions different from those stated above.

\subsection{Counterpart Funds in an Inflationary Economy}

The economies of most developing countries can rarely be described by the set of assumptions of the previous section. In a significant sense, the presence of overt problems - inflation, price distortion, balance of payments disequilibrium - has at least one advantage. A problem is explicit and can be identified and agreement reached on its resolution. Few people, for example, oppose stopping inflation.

Suppose the economy that is receiving aid is experiencing a modest, but unwelcome inflation. The inflation is diagnosed as an excess demand inflation. The argument above made it evident that counterpart funds can be used as an anti-inflation instrument. The aid commodities arrive, are sold, and the government effectively sterilizes the receipts. There are more commodities and less money, generally a pretty good anti-inflation policy. Evidently, the government can always counter this deflationary effect by printing money, but the counterpart fund process does provide a significant anti-inflation instrument. (If the inflation is rampant, it is doubtful that the counterpart fund process can be very important.) Some observers emphasize that this may be the most appropriate use of these funds. Virtually all developing countries, it is argued, experience significant upward pressure on prices. It should be a matter of routine, therefore, that counterpart funds should be sterilized, and no further use be made of them. This position, though understandable, seems to us to be unnecessarily cautious. We believe rather that a more positive use of them is possible in many instances. In particular, it is noted that under this arrangement the government does not gain any increase in command over the economy's resources. In certain circumstances, this result may be one that is sought after, but in other circumstances it may be that there is real advantage to the government acquiring more resources.

An excess demand situation is rarely 'pure', but is usually accompanied by distortions of one kind or another. Such distortions are frequently caused by inflation and they, in turn, fuel continued inflation. These structural characteristics add complexity to the task of halting the inflation without penalizing the economy. With such structural difficulties, simply reducing the money supply as the aid commodities 
become available is not sufficient, and will almost certainly result in reduced output and employment. In this context, it may be most appropriate to spend the counterpart funds, not to use them as a means of reducing the money supply. The question then becomes how to use them to correct distortions and break the bottlenecks that have forced the economy to operate inside its production possibility frontier. The idea is to use the counterpart funds to enable the government to act on the supply side as well as on the demand side, rather than go all out on the demand side. It may also be noted that in the presence of production bottlenecks, the composition of the aid commodities becomes more strategic than in the pure excess demand situation.

Since so much depends on the nature and source of distortions and bottlenecks, generalizations are difficult. An example or two may help make the argument clearer. Suppose that there is considerable underemployment in the economy, but wage rates are rising. An increase in wage rates in the face of underemployment means that the labour market is, in some way, distorted. Counterpart funds then might (it depends on why wage rates are rising) be used to correct or offset this distortion with an employment subsidy of some kind or other that would dampen the upward tendency of wages and increase output. Similarly increased outlays that had a significant effect on the capacity of the taxing bureaucracy to levy and collect more taxes might be a powerful anti-inflation expenditure. Other examples might be provided, but the general point is rather simple: we study the economy to determine where the distortions and bottlenecks exist, and ask can these be corrected by increased government expenditure. This emphasis on understanding the economy as it is currently functioning is a major consideration in later arguments on the use of counterpart funds. It should be noted that, in these examples, for counterpart funds to be useful, there must be some reason why general government revenues, raised through taxes or borrowing, cannot be used for these purposes.

\subsection{Counterpart Funds in an Economy with Balance of Payments Problems}

A balance of payments problem exists when the prevailing situation is not one that can be sustained. Imports exceed foreign exchange earnings to an extent that is not covered by long term capital flows. The excess is paid for by drawing down reserves, suppliers' credits, etc., methods that cannot be maintained very long. To cut back on imports abruptly to relieve this situation can be expected to lead to unemployment and lost output and, possibly produce inflation. Aid financed imports will then replace current imports that are being paid for by these temporary expedients and allow the country to avoid immediate curtailments in imports. These aid financed imports are not additional, but reduce the foreign borrowing or the using up of reserves that had been taking place.

In such a situation the use of counterpart funds falls mainly under the category discussed above of seeking to eliminate the sources of the distortions that prevent the economy from operating at its production frontier without inflation. In the present situation the distortions are affecting the foreign trade sector directly, and the funds might be used to act directly on imports or exports. Exactly what such uses would be depends very much on the prevailing situation. There are several suggestions as to how the aid/counterpart fund mechanism can be used to facilitate a devaluation or to act directly on increasing exports and reducing imports. One such possible role for counterpart funds may be mentioned. Suppose that both the donor and recipient agree that the latter's currency should be devalued. Both also agree that to devalue at a given time would be to initiate or feed an inflation. The funds obtained from the sale of aid commodities or foreign exchange can be used to pull money from the system that is, in effect sterilized, i.e. not returned to the economy by government spending. This process would result in a devaluation becoming feasible when otherwise it would not have been. (See Bruton and Hill 1991.)

\subsection{Counterpart Funds in Countries with Soft Government and Weak Bureaucracy}

It is useful to mention briefly an especially interesting role that counterpart funds have played in some countries where the government is in considerable disarray. In some instances the existing governments more or less turned over to a donor the counterpart funds that commodity aid produced with little or no real restrictions on their use. The funds were then used largely to provide modest services to pregnant women and new mothers, to children, to hospitals, etc. The recipient government neither helps nor objects. Some worthwhile things may be accomplished and the presence of the donor is maintained, which itself may be an advantage. Such an arrangement is something of a holding operation in anticipation of changes in the government that might allow more formal development aid programmes to be carried out. A similar use of counterpart funds is found in several countries - e.g. Bolivia and Zambia - where they have been used to establish endowments of Social Funds of one kind or another. Susan Gardiner's article in this Bulletin issue considers this use in more detail.

\section{WHY COUNTERPART FUNDS?}

We are now at the place where we can examine more 
specifically the general argument for the counterpart fund process. The basic rationale rests on our view of how development takes place and the kind of policy making and implementing that is possible in most developing countries. In the neat textbook equilibrium, with full knowledge, no institutions or values other than self interest, objective and honest government, and full agreement on development theory and practice, we saw that there is no need for counterpart funds. They would be a cost without a benefit.

Once we move into a world where these conditions are all essentially absent, the counterpart fund approach can have real value. There are institutions and practices that limit what a government can do, there are perceptions of what is acceptable, development theory and practice are open to all kinds of dispute, there is power and rent seeking and ignorance and malfeasance and uncountable other things. There are, for example, some situations in which it is as difficult for a government to gain access to local currency as it is for the government to get foreign exchange (See Singer 1987). Indeed there are examples of countries that pressed donors for food aid, not because they needed the food, but because the government needed the local currency that food aid would make possible for them to have.

What gives counterpart funds so much potential is this: they provide a means by which these characteristics institutions that create constraints, ignorance, conflicting values - are recognized and taken into account, and still something can be accomplished. To use counterpart funds effectively in these circumstances requires considerable knowledge about the recipient economy by both donor and recipient. One looks at an economy and sees many difficulties and problems standing in the way of increasing the well-being of the people. Then we try to identify where it might be effective to try to do something. This approach requires that it be possible to identify constraints that are presently impeding economic performance, and designing a policy for breaking those constraints. Counterpart funds are sometimes peculiar in that things can be done with them that cannot be done with ordinary governmental revenues. Some examples are given below.

Such an exploitation of counterpart funds requires, not only knowledge of the state of the economy, but flexibility and responsiveness on the part of the donor. Of equal importance is that their effective use requires a great deal of conversation with the relevant authorities in the developing countries. The approach requires conversation - not leverage or conditionality - because it does recognize that the institutions, traditions, practices, ideas peculiar to the country are highly relevant in determining what can be done, and what, indeed, should be done. Hence general principles cannot be the full story.

We put great weight on this issue for two main reasons. There are signs that the revived interest in counterpart funds has arisen from the expectation that they do serve as a source of leverage, as a means of getting the recipients to do what the donor thinks that they should do. This we do not believe. In general we doubt that policies and ideas that are forced on a government without its genuine agreement and understanding will have much lasting effect.

The second reason for putting weight on this issue links with our earlier argument: in a situation where broad general principles cannot be applied directly and universally, and where consideration must be given to the content of the specific economic, social, and political environment, then knowledge of that environment is crucial, and nationals, of course, know more about such matters than donors can ever know.

\section{SOME EXAMPLES}

We studied a great number of instances of the use of counterpart funds by the United States Agency for International Development (Bruton and Hill 1991). These cases revealed, in one way or another, all of the aspects discussed in the preceding pages, as well as some of the points from our earlier article on macro effects.

\subsection{Costa Rica}

The clearest example of an unusually effective exploitation of counterpart funds took place in Costa Rica in the early 1980s. During the early 1980s the United States provided Costa Rica with substantial cash grants which in turn generated large amounts of counterpart funds. The Government of Costa Rica and the United States aid personnel agreed that to spend these funds at that time would be inflationary. They agreed that their continued accumulation would have unfortunate political consequences for both countries. It was also recognized that a major source of Costa Rica's financial difficulties arose from the fact that publicly owned companies were losing large sums of money on a regular basis.

In this context the Director of the United States aid programme in Costa Rica maintained a continuing dialogue with Costa Rican officials on the advantages of the government disposing of these companies to private sector interests. The companies owed the Central Bank large amounts of money, and these debts were a major obstacle to their purchase by the private sector. The Government of Costa Rica and the United States aid mission then agreed to use the accumulated counterpart funds to 'pay off these debts. This transaction 
consisted simply of a few bookkeeping entries. While in some technical sense, the debts could have been written off by the Central Bank, the rules and practices prevailing made such a thing so awkward and politically risky that it surely would never have been done. The counterpart funds then allowed the debts to be removed, and a major contribution was made to the country's development programme. It seems clear to us that such a privatization effort could not have taken place in the absence of counterpart funds.

\subsection{Mozambique and Dominican Republic}

In 1987, the government of Mozambique adopted a stabilization programme, the Economic Rehabilitation Program (ERP). The programme included strict fiscal and monetary policies under the auspices of the IMF and IBRD. The use of counterpart funds was constrained by the IMF targets for the government budget and the money supply. The USAID mission believed that its use of counterpart funds should support the IMF programme. It therefore believed that stabilizing the economy was a necessary, if not sufficient, condition for improved growth in Mozambique.

The counterpart funds were to be used to finance part of the government deficit. Since the monetary effects of financing the deficit were already in the monetary programme, uses of the counterpart funds were included in the monetary targets. (The only way that spending the counterpart funds would contribute to violating the credit targets would be if spending increased above previously planned levels, and therefore the deficit increased, and this increase was financed by additional counterpart funds.)

The counterpart funds were allocated 'for attribution' to the areas in the budget consistent with AID objectives. Under the economic conditions in Mozambique, not uncommon in developing countries, the aid and counterpart funds were contributing to stabilization by easing the balance of payments constraint and increasing resources available to the government. If the donor agreed with the IMF/IBRD goals, then in programming the counterpart funds, these goals would be supported. A major mistake would be to programme counterpart funds accumulated in previous years on expenditures not in the government budget agreed to in the stabilization programme. This would increase the deficit and domestic credit to the government and violate the monetary targets. Less clear was whether the donor should attempt to influence the allocation of resources within the given level of government expenditures agreed to in the stabilization programme. The IMF worried that protecting certain categories of expenditures within a constrained total level of spending would lead to a skewed, not better, allocation of resources. By programming the counterpart funds 'for attribution', USAID was not having much, if any, effect on resource allocation through the counterpart funds mechanism as such; USAID did have some role in the determination of the overall size and allocation of the government budget.

This example raises the issue of when agreement should be reached on how the counterpart funds should be programmed. It is often argued that agreement should be reached when the aid is transferred. The argument is that this is the point at which the donor is in the strongest position. But if this is done, and then economic circumstances change, for example a stabilization programme is adopted, the agreement reached on counterpart funds spending may not coincide with stabilization goals. In cases like this, the donor should be flexible about agreements previously reached.

The AID programme in the Dominican Republic is a slight variation of the Mozambique story. A major component of the AID strategy (1986/87) was the sustained implementation of the economic stabilization programme. At the same time, the Aid Evaluation (Jafri et al. 1988) states that the joint programming of the counterpart funds permitted the United States to advance AID programme objectives and to apply conditionality effectively. The types of programmes for which the counterpart funds were programmed were examined. At the same time, the stabilization programme included constraints on domestic credit and on any counterpart funds programmed to contribute to the domestic credit target. Therefore, in contrast to Mozambique, USAID attempted to influence the allocation of resources in the overall budget, and did not simply programme counterpart funds 'for attribution'. It is not clear why this decision was made in the case of Dominican Republic and not Mozambique and whether there were benefits to doing this.

The Mozambique and Dominican Republic cases demonstrate that the aid plus counterpart funds mechanism can contribute to development by facilitating macroeconomic stabilization. The Dominican Republic story suggests that in some cases it may be possible to contribute to stabilization, and, within the government budget consistent with stabilization, have some influence on allocation decisions. It should be kept in mind, however, that if stabilization is a primary concern, then in general, it should not be sacrificed to influence resource allocation.

The 'FY 1985 Evaluation of the Bangladesh Program' (p 35) brings this last point out:

. . the importance of policy dialogue, however 
imprecise and non-quantifiable it may sometimes be, can in many instances be paramount over discrete matters as how many miles of canal are built here, or what number of pumps have been placed in operation there, or was the accounting of that activity up to developed countries' standards?

As a matter of sovereign pride, developing country governments feel they can accept only so much 'guidance' in return for a given level of assistance, so it follows that increased US government intervention in their affairs in areas of minor objective importance may result in diminished ability to influence them in areas that are truly critical.

The stabilization issue is one example of this. If considered vital, aid and counterpart funds should be used in a way that supports the stabilization goal.

\subsection{Jamaica}

The evaluation of the cash transfer programme in Jamaica (Nathan Associates 1988) illustrates the difficulty of getting the monetary effects of counterpart funds completely correct:

When cash transfer dollars are provided to the GOJ they can be used to finance imports, pay debt arrears, or added to foreign exchange reserves. No matter which use is chosen, an equivalent amount of local currency will be created. If the dollars are applied to debt repayment or added to foreign exchange reserves, there will be no immediate increase in imports but there will initially be an increase in local currency. With an increase in the money supply and no increase in the availability of goods, the effect will be inflationary in the near term. The GOJ creates additional local currency but no additional goods are available. If, on the other hand, the AID cash transfer is used to finance imports, there is an increase in imported goods and an equivalent amount of local currency withdrawn from the economy. There is no inflationary impact. In the longer term, the inflationary impact of a given cash transfer is likely to be neutralized. Even if the dollars are not used for imports in the near term, they presumably will be eventually (since either debt repayment or additions to reserves bolster a country's import capacity). The effect, therefore, is likely to be one of leads and lags: initially inflationary, later deflationary. (p 76)

This statement is not quite complete. Counterpart funds are government deposits at the Central Bank. When the government receives a cash transfer, counterpart funds are generated when it sells the foreign exchange to the Central Bank or the private sector. In the former case, the money supply is initially left unchanged. If instead the government sells the foreign exchange to the private sector, high powered money declines. To determine the final effect of the aid and counterpart funds on the money supply, the effects on the balance of payments and the government budget must be analyzed. Assume, in Jamaica's case, that the government deficit does not increase as a result of the aid (the initial levels of expenditures and taxes remain unchanged). Assume further that the government has generated the counterpart funds by selling the foreign exchange to the Central Bank. Initially, there is no effect on the money supply, and the amount of borrowing from the Central Bank required to finance the government deficit remains unchanged. If imports increase from what they would have been otherwise, net foreign assets at the Central Bank will decrease, decreasing high powered money and the money supply. If imports remain constant, then nothing changes. In the Jamaican study, the monetary effects as already described are not completely worked out, either on initial impact or after the balance of payments or government deficit effects are incorporated.

This example is a useful one for showing that the initial effect of the counterpart funds on the money supply can result in confusion about the final or total monetary effects of counterpart funds. As previously mentioned, the initial monetary effect differs if the government sells the foreign exchange to the private sector rather than the Central Bank. But, ultimately, this is irrelevant. To see this, if imports do not increase from previous levels, the private sector has no use for the foreign exchange. Purchases of foreign exchange that otherwise would have taken place, will not be needed now. Net foreign assets at the Central Bank will be higher by this amount. The effect of this (which increases high powered money from what it otherwise would be) plus the first round impact effect (which reduces the high powered money) leaves the money supply unchanged. This is the same final effect on the money supply if the aid is sold to the Central Bank in the first place and imports do not increase.

\subsection{Other Countries}

Other examples are less clear, but often of relevance. In some countries (e.g. Pakistan) the existence of counterpart funds led to a continuing conversation on their use between the United States and Pakistan that convinced both countries that it was in order for Pakistan to spend more of its development budget on health and elementary education. In Haiti, where the government is more or less uninterested in development, an informal arrangement between the United States and the Haitians allowed the former to use the counterpart funds more or less as it wished. The result was some useful studies on various aspects of Haiti as well as some direct services to certain poor groups. Any sort of institutionalization of the aid programme was not possible, given the Haitian government, but the counterpart funds made possible some activities that 
made modest contributes to an otherwise dismal environment. Similar stories apply to Liberia and Zaire. In Tunisia there is evidence that the discussions surrounding the use of counterpart funds helped both Tunisia and the donor to understand more clearly the constraints that presently were effective in that country. Egypt provides an example of another sort. The United States aid programme to Egypt is dominated by political and strategic factors. This fact makes it very difficult for the United States to have any role at all in influencing Egyptian policy simply because it provides substantial aid. The availability of counterpart funds did, however, make it possible to support the American University of Cairo. Without the flexibility allowed by counterpart funds, such support would not have been possible. We also found instances in several countries where it seemed fairly clear that the process had no significant advantage, and was largely a nuisance with substantial administrative costs. This was probably the case in Pakistan at certain times when the United States aid personnel had an especially effective rapport with the Pakistani officials. Similarly, in India in the early 1960 s the counterpart funds were surely unnecessary, and indeed created some tension between India and the United States until they were eventually simply written off.

\section{CONCLUSIONS}

To repeat our general position: all aspects of development - what it is, the design and implementation of 'right' policies, the respect of institutions and values of society, etc. - prevent a neat transparent approach to foreign aid. The counterpart funds procedure seeks then to recognize this complexity, ambiguity and ignorance, and to use the flexibility and peculiarities of their existence to accomplish things that otherwise could not be accomplished.

\section{REFERENCES}

Bruton, H. J. and Hill, C. B., 1991, The Development Impact of Counterpart Funds, Washington DC, Agency for International Development. (This document provides an elaboration of most of the points discussed in this Bulletin article)

Jafri, M. H., Eaton, S. and Sequevia, G., 1988, The Effectiveness and Economic Development Impact of Policy-Based Cash Transfer Programs: The Case of the Dominican Republic

Lewis, J. P., 1962, Quiet Crisis in India, The Brookings Institution, Washington DC

Little, I. M. D. and Clifford, J. M., 1965, International Aid, Aldine Publishing Company, Chicago
Mason, E. S., 1960, 'Foreign money we can't spend', The Atlantic Monthly, May

Robert Nathan Associates, 1988, Jamaica Cash Transfer Evaluation

Singer, H. W., 1964, International Development: Growth and Change, Chapter 15, McGraw-Hill, New York

-Wood; J. and Jennings, T., 1987, Food Aid: The Challenge and the Opportunity, Clarendon Press, Oxford

United States Agency for International Development Publications FY 1985 Evaluation of the Bangladesh Program 